\title{
THE INTERPRETATION OF PULMONARY ARTERY WEDGE (PULMONARY CAPILLARY) PRESSURES
}

\author{
BY \\ WILLIAM H. BERNSTEIN, EUGENE M. FIERER, MAURICE H. LASZLO, \\ PHILIP SAMET, AND ROBERT S. LITWAK \\ From the Cardio-Pulmonary Laboratory, Mt. Sinai Hospital, Miami Beach, and the Departments of \\ Medicine and Surgery, University of Miami School of Medicine, Coral Gables, Florida, U.S.A.* \\ Received February 3, 1959
}

The development of right heart catheterization (Cournand and Ranges, 1941) has permitted direct evaluation of right heart hæmodynamics. Attempted extension of such measurements to the left side of the heart led first to the determination of pulmonary artery wedge ("pulmonary capillary") pressures (Hellems et al., 1948, and Lagerlof and Werkö, 1949) and thence to direct left heart catheterization (Fisher, 1955). The purpose of this paper is to demonstrate the limitations of the pulmonary artery wedge pressure, by illustration of various vagaries in its form and of problems in its interpretation.

\section{Methods AND Materials}

The physical characteristics and diagnoses in 28 patients are given below. Right heart catheterization was performed in the usual manner, with the subject supine in the basal post-absorptive state. Left heart catheterization was performed as previously described (Samet et al., 1959) by a modification of the posterior percutaneous puncture of Fisher. The zero level for right heart and pulmonary artery wedge pressures supine was $5 \mathrm{~cm}$. dorsal to the angle of Louis. The zero level for left heart pressures was $10 \mathrm{~cm}$. dorsal to the angle of Louis in either the supine or prone position.

The tip of the right heart catheter was wedged in the usual manner. Oxygenated blood could not be aspirated from the tip (in the wedge position) in most instances. Verification of the adequacy of wedging was obtained during the pull-back from the wedge position to the pulmonary artery position. In all cases the catheter loop "wound up" in a small coiled loop before the tip snapped back into the pulmonary artery from the wedge position. The upper limit of normal of the wedge pressure was taken as $12 \mathrm{~mm}$. $\mathrm{Hg}$.

Double- or triple-lumen right heart catheters were employed in most studies. In both types there is one opening at the tip and another $12 \mathrm{~cm}$. proximal to the tip. In the triple-lumen catheter, the third opening is located $27 \mathrm{~cm}$. from the tip.

\section{RESULTS}

Peculiarities in the form or level of the pulmonary artery wedge pressure were noted in 28 patients. These represented more than 10 per cent of all patients undergoing cardiac catheterization in the period of this study. Four types of vagaries in the wedge pressure were found. In the first (11 subjects), false or unexplained elevation of the pulmonary artery wedge pressure was noted. This elevation was recorded in some subjects with rheumatic heart disease in the absence of a significant 
mean diastolic left atrial-left ventricular gradient and in the presence of a normal left ventricular end-diastolic pressure. False elevations were also noted in some patients with cor pulmonale or congenital heart disease.

In the second type (10 patients), a normal pulmonary artery wedge pressure was found in the presence of a significant mean diastolic left atrial to left ventricular gradient ( $5 \mathrm{~mm} . \mathrm{Hg}$ or more). In the third type (11 patients), large variations in the level of the wedge pressure were noted in different or the same wedge position. In the last type (3 patients), spontaneous variations in the degree of wedging were recorded. The total of patients in these four groups was more than 28 because some subiects were included in more than one category.

Type I. Case 1, a 35-year-old white man, had aberrant pulmonary venous connection and drainage. The pulmonary vein draining the right lower lobe emptied into the inferior vena cava. On right heart catheterization with a triple-lumen catheter, false elevation of the pulmonary artery wedge pressure was observed (Fig. 1). The wedge pressure was recorded at over 100 and $200 \mathrm{~mm}$. Hg; pulmonary artery and right ventricular systolic pressure were both $22 \mathrm{~mm}$. Hg. Case 2, a 33-year-old white man with rheumatic heart disease, was studied seven months after mitral valvotomy. Pulmonary artery wedge, right ventricular and pulmonary artery pressures were recorded simultaneously. The mean wedge pressure was greater than the right ventricular systolic pressure, an anomalous observation. A similar finding was noted in Case 3, a 23-year-old white man with rheumatic heart disease. Comparable pressure curves were recorded in Case 4, a 35-year-old white woman with rheumatic heart disease. Case 5, a 40-year-old white man had rheumatic heart disease with mitral stenosis. The pre-operative pulmonary artery wedge pressure was $19 \mathrm{~mm} . \mathrm{Hg}$; the mean diastolic left atrial to left ventricular gradient was $13 \mathrm{~mm}$. Hg supine. One month after operation the wedge pressure was $8 \mathrm{~mm}$. $\mathrm{Hg}$. Ten months after, the wedge pressure was again elevated at $14 \mathrm{~mm} . \mathrm{Hg}$, but the left atrial to left ventricular gradient was only $2 \mathrm{~mm} . \mathrm{Hg}$ at rest and 3 during exercise. Left atrial mean pressure was $10 \mathrm{~mm}$. $\mathrm{Hg}$, and the left ventricular end-diastolic pressure $11 \mathrm{~mm} . \mathrm{Hg}$. Case 6, a 38-year-old white woman, had rheumatic heart disease; wedge pressures with a triple-lumen catheter gave peculiar results (Fig. 2). A delayed pulmonary artery curve was recorded from the tip (uppermost curve) at a level higher than the true pulmonary artery and right ventricular systolic levels. On re-wedging in another area, the wedge pressure was of the more expected pattern (Fig. 3). Case 7, a 38-year-old coloured woman had aortic stenosis, rheumatic or congenital in origin. Left ventricular end-diastolic and left atrial mean pressures were normal. Pulmonary artery wedge pressure varied considerably with respiration at or above pulmonary artery systolic pressure. Case 8, a 44-year-old white woman, had rheumatic aortic stenosis and regurgitation. Simultaneous recording of pulmonary artery and pulmonary artery wedge pressures (Fig. 4) was performed. The latter, starting from a level well above pulmonary artery systolic pressure, fell continuously during the recording, finally falling to zero. On flushing the tip lumen and again recording pressures, the same phenomenon was observed. Case 9, a 37-year-old white man, had a patent ductus arteriosus with pulmonary hypertension and a consequent reversal of the shunt. Pulmonary artery wedge pressures varied from $40-80 \mathrm{~mm}$. $\mathrm{Hg}$ in a single run. Case 10, a 39-year-old coloured man suffered from obstructive pulmonary emphysema and sarcoidosis. Pulmonary artery wedge pressures of 40 and $37 \mathrm{~mm}$. $\mathrm{Hg}$ were recorded. Case 11, a 40-year-old white man, had rheumatic aortic stenosis. Normal mean left atrial and left ventricular end-diastolic pressures were recorded, but the pulmonary artery wedge pressure was elevated to $18 \mathrm{~mm}$. $\mathrm{Hg}$.

Type II. This group includes 9 patients with normal pulmonary artery wedge pressures (upper limit of normal $12 \mathrm{~mm}$.) but with significant left atrial to left ventricular mean diastolic gradients (Table 1). In the tenth patient (Case 21), the pre-operative wedge pressure varied from $10-17 \mathrm{~mm}$. $\mathrm{Hg}$ during three different catheterizations. The pre-operative atrio-ventricular gradient was $14 \mathrm{~mm}$. $\mathrm{Hg}$. Case 12, a 49-yearold white man, had rheumatic mitral regurgitation and stenosis. Pulmonary artery mean wedge pressure was zero during the first catheterization (Fig. 5). The mean diastolic left atrial to left ventricular gradient was $10 \mathrm{~mm}$. Hg (Fig. 6). Similar observations were made in Case 13, a 48-year-old white man with mitral stenosis (Fig. 7 and 8); in Case 14, a 49-year-old white man with mitral stenosis; in Case 15, a 32-year-old white man with mitral and aortic stenosis and aortic regurgitation; in Case 16, a 54-year-old white woman with mitral stenosis; in Case 17, a 49-year-old white woman with mitral stenosis and regurgitation and in 3 patients with mitral stenosis (Cases 18,19 , and 20 ) aged 48,46 , and 49 years respectively.

Type III. Large variations in the level of mean pulmonary artery wedge pressure were recorded in these patients (Fig. 9, Case 2). Similar observations were made in Case 4, a 35-year-old white woman with aortic 


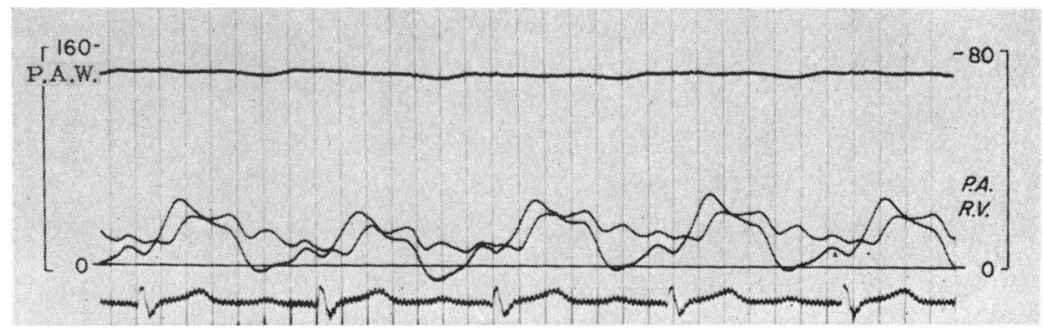

FIG. 1.-Simultaneous pulmonary artery (P.A.), right ventricular (R.V.), and pulmonary artery wedge (P.A.W.) pressures in Case 1. The magnitude of the latter pressure is in a non-physiological range.

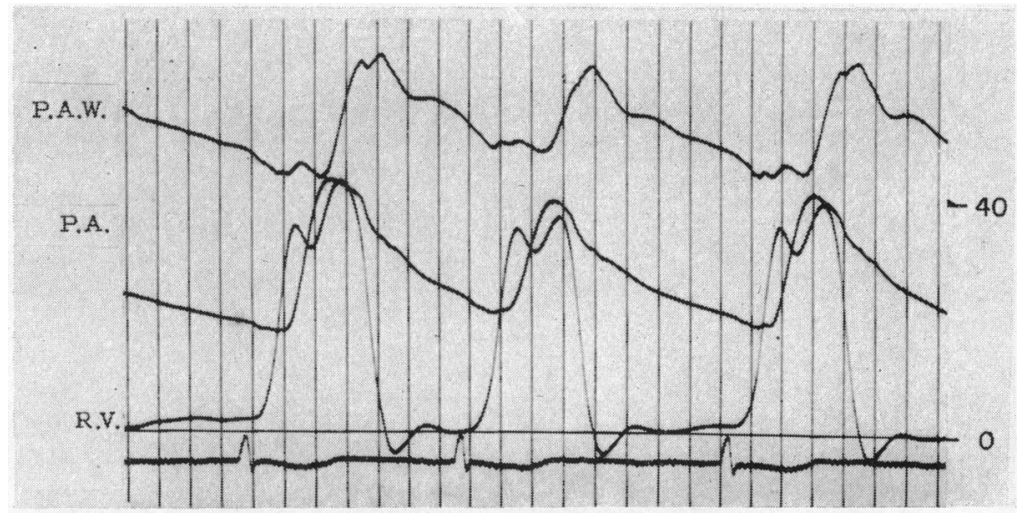

FIG. 2.-Right heart pressures in Case 6 recorded with equisensitive gauges. The uppermost curve was recorded from the wedged catheter tip and has the form of a delayed pulmonary artery curve. The lower two curves are from the pulmonary artery and right ventricle. Note the delayed falsely elevated pressure curve obtained from the wedged tip.

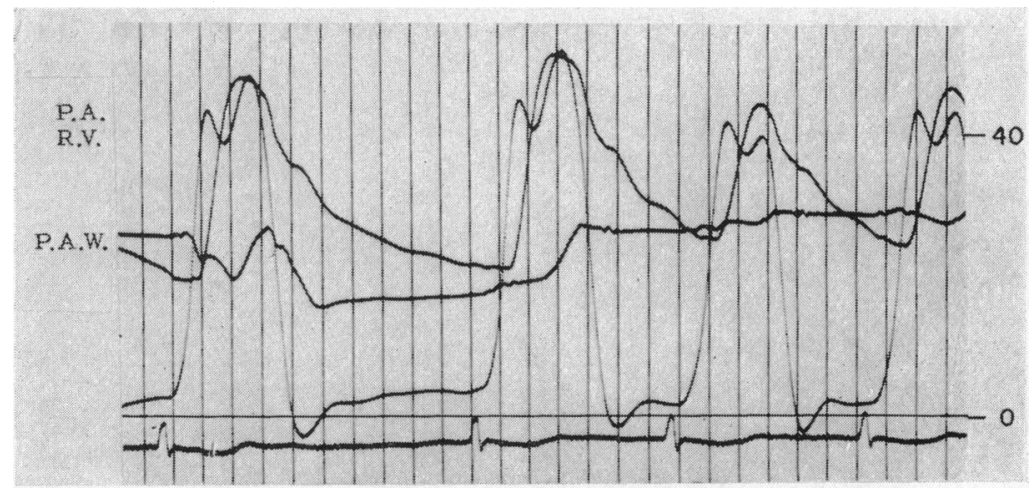

FIG. 3.-A more usual wedge curve obtained by re-wedging of the catheter tip in Case 6. 


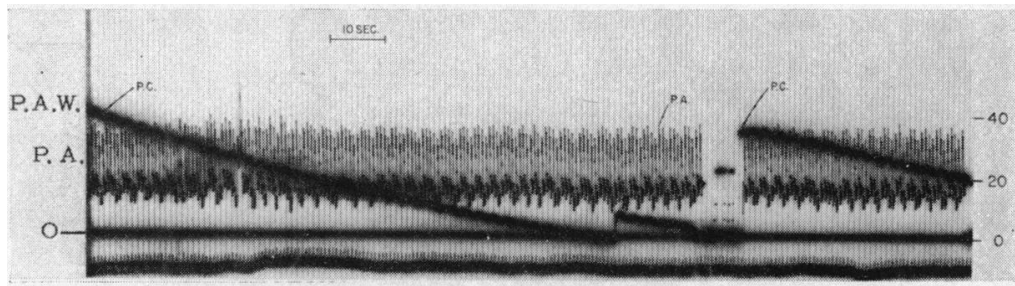

Fig. 4.-Pulmonary artery wedge (P.A.W.) and pulmonary artery curves (P.A.) in Case 8. A continuously changing falling wedge pressure was reproducibly recorded.

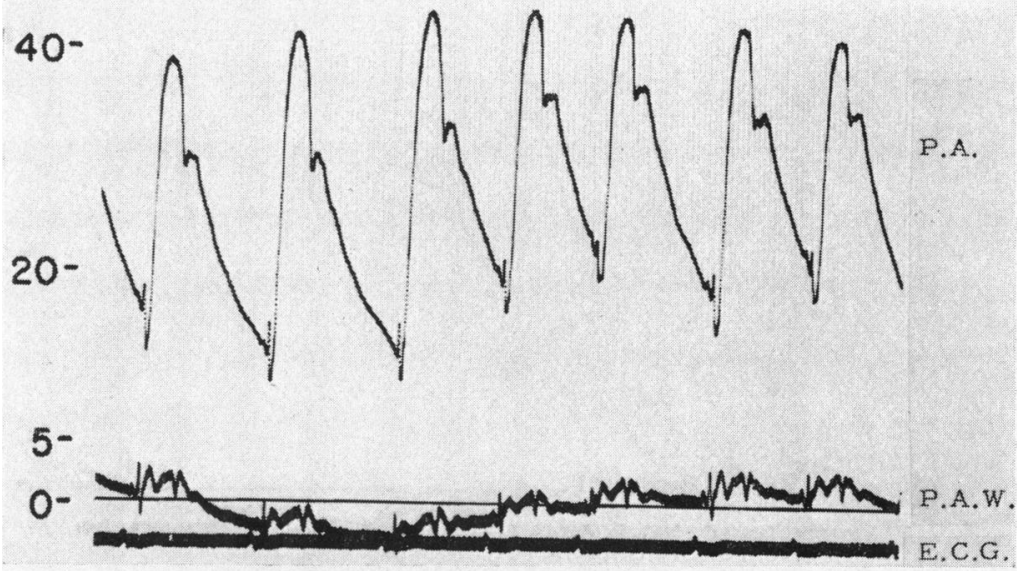

FIG. 5.-Pulmonary artery (P.A.) and pulmonary artery wedge pressures (P.A.W.) in Case 12. The latter pressure is zero in a patient with mitral stenosis and regurgitation.

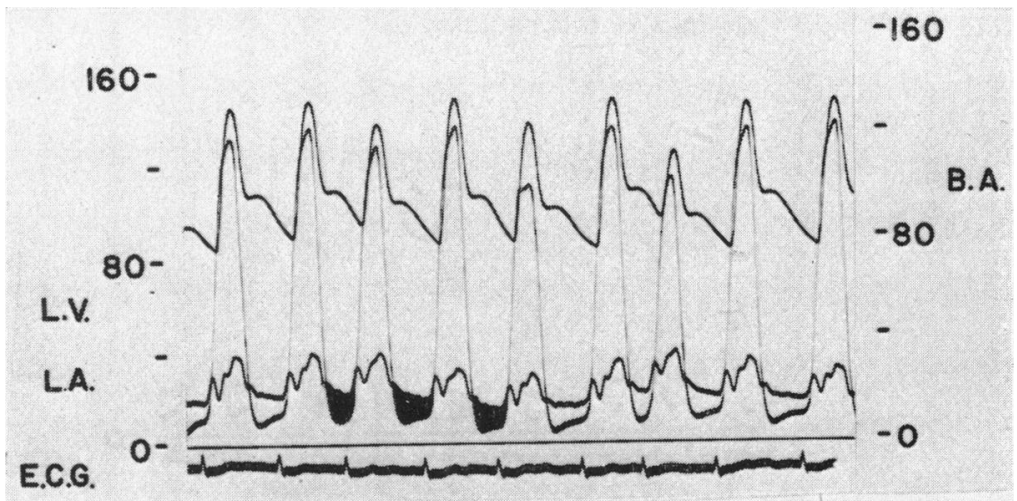

FIG. 6.-Left atrial (L.A.), left ventricular (L.V.), and brachial artery (B.A ) curves in Case 12. There is a significant left atrial to left ventricular mean diastolic gradient (shaded area). 


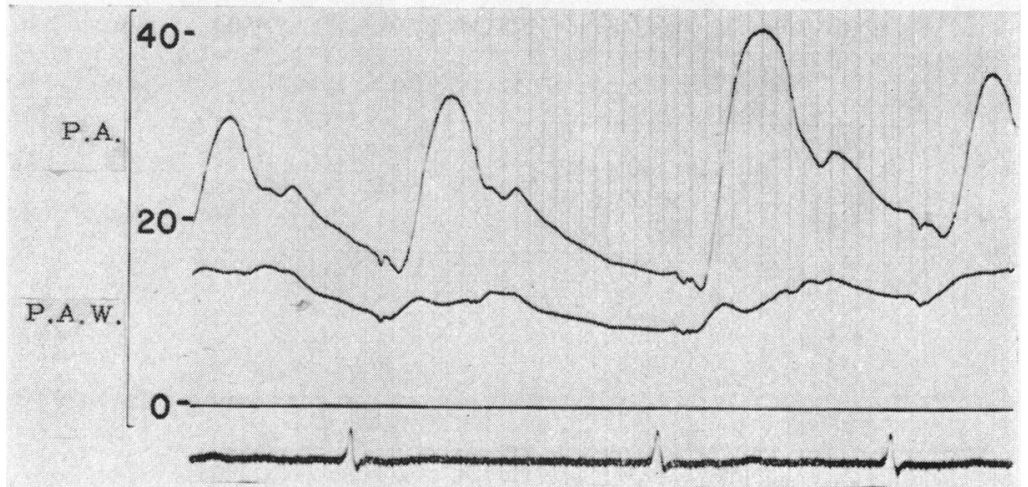

FIG. 7-Pulmonary artery (P.A.) and pulmonary artery wedge (P.A.W.) pressures in Case 13. The latter pressure is at the upper limit of normal in a patient with surgically verified tight mitral stenosis.

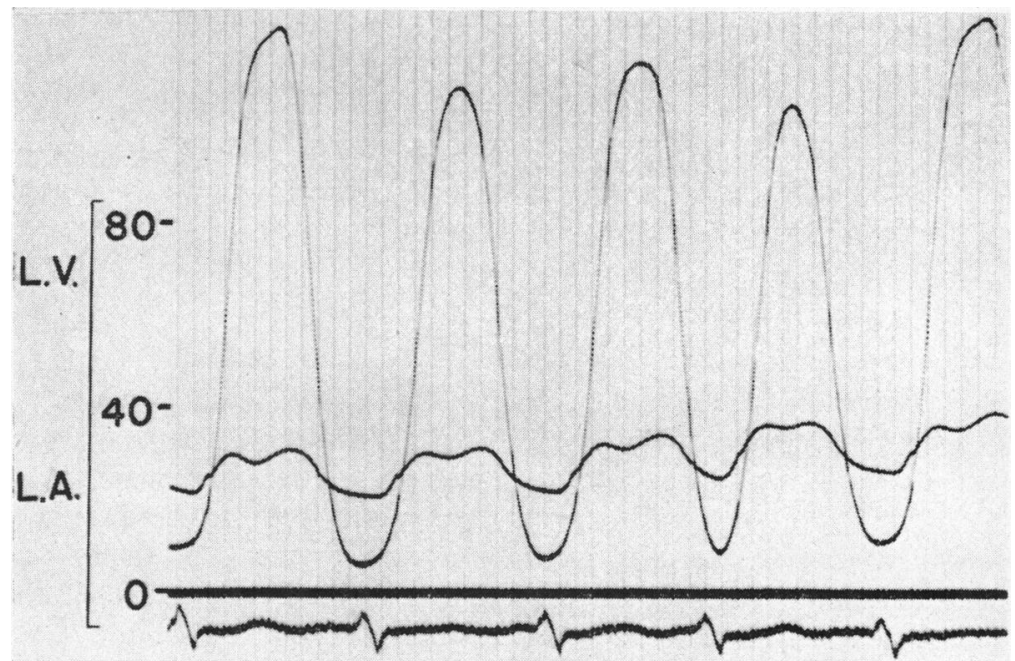

FIG. 8.-Left atrial (L.A.) and left ventricular (L.V.) pressures in Case 13. The mean diastolic left atrial to left ventricular gradient is readily seen.

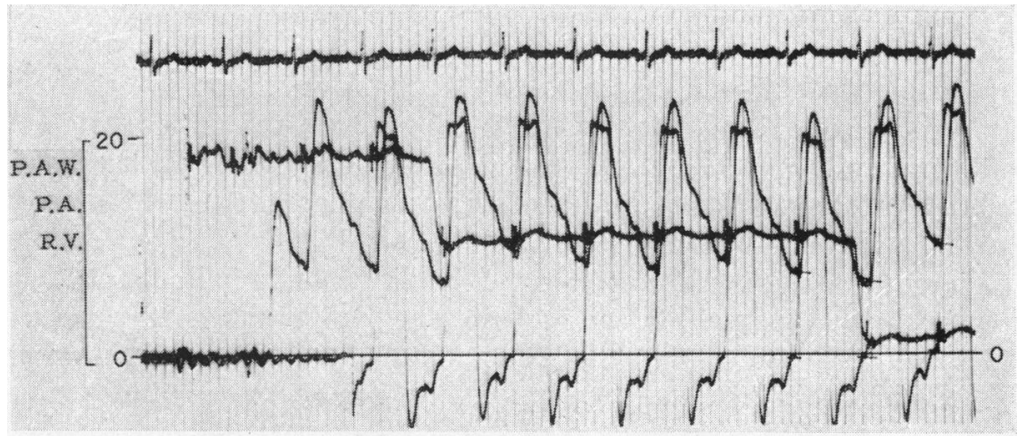

FiG. 9.--Pulmonary artery wedge (P.A.W.), pulmonary artery (P.A.), and right ventricular (R.V.) curves in Case 2. Three levels of pulmonary artery wedge pressure are recorded in one short strip of tracing (All pressures recorded in $\mathrm{mm}$. $\mathrm{Hg}$.) 
TABLE I

Comparison of Pulmonary Artery Wedge Pressure Supine and Left Atrial to Left Ventricular Mean Diastolic Gradient in the Prone Position

\begin{tabular}{c|c|c}
\hline Case No. & $\begin{array}{c}\text { Pulmonary artery } \\
\text { wedge pressure, } \\
\text { mm. Hg. }\end{array}$ & $\begin{array}{c}\text { Mean diastolic L.A.-L.V. } \\
\text { gradient, mm. Hg, with } \\
\text { the patient prone }\end{array}$ \\
\hline 14 & 12 & 10 \\
12 & 0,10 & 11 \\
15 & 12 & 12 \\
13 & 12 & 9 \\
16 & 7 & 9 \\
17 & 11 & 16 \\
18 & 11 & 9 \\
19 & 12 & 8 \\
20 & 10 & 10 \\
21 & $17,15,10$ & 14 \\
\hline
\end{tabular}

and mitral insufficiency; in Case 22, a 31-year-old white woman with mitral and aortic stenosis and aortic regurgitation; in Case 23, a 39-year-old white man with aortic stenosis and regurgitation; in Case 24, a 42year-old white man with mitral stenosis; in Cases 3,6,9, and 11 (described above); and in Case 25, a 59-yearold white man with mitral stenosis.

Type IV. Pronounced variations in the degree of wedging were noted in this group which included Case 26, a 39-year-old white woman 5 years after mitral valvotomy; Case 27, a 14-year-old white girl with a ventricular septal defect; and Case 28, a 39-year-old white woman with heart disease of undetermined ætiology.

\section{Discussion}

The technique of wedging a right heart catheter in a peripheral branch of the pulmonary artery was initially developed by Hellems et al., 1948. The significance of this pressure has since been investigated extensively both in man and the experimental animal (Hellems et al., 1949; Ankaney, 1953; Connolly et al., 1954 and 1957; Wiggers, 1953; and Burton, 1953). Despite theoretical objections (Wiggers 1953 and Burton 1953) pulmonary artery wedge pressure has been generally accepted as an approximation of mean left atrial pressure. However, both theoretical and practical difficulties have resulted. One patient (Spodick and Littman, 1958) underwent mitral valvotomy on two separate occasions because pulmonary artery wedge pressures of 24 and $27 \mathrm{~mm}$. $\mathrm{Hg}$ at rest were found on two right heart catheterizations. On exercise, the wedge pressure rose to $33 \mathrm{~mm}$. Hg. The calculated "mitral valve areas" were 1.6 and 0.94 sq. $\mathrm{cm}$. A normal mitral valve was found at both surgical procedures and at the post-mortem examination following the second thoracotomy.

The pulmonary artery wedge pressures shown in this paper were recorded in the usual fashion by advancing the tip of the catheter as far as possible in a branch of the pulmonary artery. The usual snap-back was noted when the tip was withdrawn into a main pulmonary artery. Fully saturated blood could rarely be withdrawn from the tip of the wedged catheter. Similar experiences have been reported by others (Pederson, 1956).

Several basic types of difficulties have been noted in this laboratory in connection with recording of pulmonary artery wedge pressures. In the first category, pulmonary artery mean wedge pressures well above pulmonary artery and right ventricular systolic peaks have been recorded. In some instances (Fig. 1), the rises were of such a pronounced degree as to raise serious doubts as to their physiologic meaning. Wedging the tip of a triple-lumen catheter led to a delayed falsely elevated pulmonary artery curve at an abnormally high level in another patient in this group (Fig. 2). Withdrawal of the tip and re-wedging the tip in another area led to a more "normal" wedge curve (Fig. 3). It is apparent that reliance upon the level of pulmonary artery wedge pressure to delineate 
those patients with mitral stenosis with significant valve block and left atrial hypertension from those without valve block (but with the murmur of mitral stenosis) may lead to serious diagnostic errors.

Unexplained elevation of wedge pressure has been noted by other investigators. Robin and Burwell (1957), have reported three patients in whom the wedge pressure was higher than the pulmonary artery diastolic pressure. This finding was attributed to technical error. Morrow et al. (1958) described two patients with elevated pulmonary artery wedge pressures: both had congenital aortic stenosis with normal ventricular end-diastolic pressures, and neither had clinical nor hæmodynamic evidence of mitral valve disease despite the wedge pressure elevation.

On the other hand, normal pulmonary artery wedge pressures have been recorded in patients with proven mitral valve block. The absolute level of left atrial pressure in these patients in the second category is of lesser importance in evaluation of mitral valve block than the presence of a significant left atrial to left ventricular mean diastolic gradient. The absolute relationship between the mean pulmonary artery wedge pressure and mean left atrial pressure when supine has been discussed in a previous study in 22 patients (Samet et al., 1959). It was noted therein that the average mean wedge pressure was $14 \mathrm{~mm}$. and the average left atrial mean pressure, $17 \mathrm{~mm}$. $\mathrm{Hg}$. The average difference, regardless of the sign, was $3.5 \mathrm{~mm}$. $\mathrm{Hg}$. This reasonably close agreement between the wedge and left atrial pressures (in the face of 9 subjects with normal pulmonary artery wedge pressures but significant left atrial to left ventricular mean diastolic gradients) demonstrates that similarity of left atrial and wedge pressures does not permit the conclusion that the wedge pressure may be used as a measure of the degree of mitral valve block. The possibility of diagnostic error is even greater in these subjects in the second group than in those in the first group, if right heart catheterization alone is employed to aid in determination of surgical indications in patients with mitral stenosis.

Marked variations in the level of the pulmonary artery wedge pressure were noted in some subjects in the third group. In Fig. 9 three different levels of mean wedge pressure are readily noted. It is problematical as to which one of these three levels represents the true "wedge pressure". An even more obvious example is noted in Fig. 4 where a continued fall in the level of pulmonary artery wedge pressure is seen: the final pressure is at the zero level. This phenomenon was reproducible after flushing the catheter tip with 5 per cent glucose in water. Similar anomalous curves were recorded in Case 4.

A difference of left atrial and pulmonary artery wedge pressures has been noted in the dog. Miliary pulmonary embolization with starch led to a rise in pulmonary artery wedge and pulmonary venous pressures without a change in left atrial mean pressure; this dissociation has been attributed to pulmonary venous constriction (Singer et al., 1957). Spasm of the pulmonary vein at its junction with the left atrium also followed intravenous injection of 20 per cent sodium chloride in the dog (Eliakim et al., 1958).

The purpose of this discussion is not to deprecate the clinical value of the pulmonary artery wedge pressure measurement, but to point out the limitations of this determination and to indicate some of the problems encountered in this laboratory in the clinical and physiological application of the wedge pressure. Other problems in the interpretation of wedge pressure have been outlined elsewhere (Pederson, 1956, and Murphy, 1958).

\section{SUMMARY}

Problems arising in the interpretation of pulmonary artery wedge pressures in patients with rheumatic and congenital heart disease and cor pulmonale have been illustrated. These difficulties have been observed in about 10 per cent of the right heart catheterizations performed in this laboratory. Unexplained elevation of wedge pressures, normal wedge pressures in the face of significant left atrial to left ventricular mean diastolic gradients, and unexplained variations in the level of wedge pressure in one study constitute the main problems causing these difficulties in interpretation of the significance and meaning of pulmonary artery wedge pressure. 


\section{REFERENCES}

Ankaney, J. L. (1953). Circulation Res., 2, 434.

Burton, A. C. (1953). Ann. Rev. Physiol., 15, 213.

Connolly, D. C., Kirklin, J. W., and Wood, E. H. (1954). Circulation Res., 2, 434.

- and Wood, E. H. (1957). J. Lab. clin. Med., 49, 526.

Cournand, A., and Ranges, H. A. (1941). Proc. Soc. exper. Med. Biol., 46, 462.

Eliakim, M., Rosenberg, S. Z., and Braun, K. (1958). Circulation Res., 6, 357.

Fisher, D. L. (1955). J. Thor. Surg., 30, 1955.

Hellems, H. K., Haynes, F. W., Dexter, L., and Kenney, T. D. (1948). Amer. J. Physiol., $155,98$.

-

Lagerlof, H., and Werkö, L. (1949). Scandinav. J. clin. Lab. Invest., 1, 147.

Morrow, A. G., Sharp, E. H., and Braunwald, E. (1958). Circulation, 18, 1091.

Murphy, J. P. (1958). Circulation, 17, 199.

Pederson, A. (1956). The Venous Pressure in the Pulmonary Circulation. Arnold Busch, Copenhagen, p. 286.

Robin, E. D., and Burwell, C. S. (1957). Circulation, 16, 730.

Samet, P., Litwak, R. S., Bernstein, W. H., Fierer, E. M., and Silverman, L. M. (1959). Circulation, $19,517$.

Singer, D., Saltzman, P. W., Rivera-Estrada, C., Pick, R., and Katz, L. N. (1957). Amer. J. Physiol., $191,437$. Spodick, D. H., and Littman, D. (1958). Amer. J. Cardiol., 1, 610.

Wiggers, C. J. (1953). Circulation Res., 1, 371. 